\title{
Accelerating the Execution of Construction Projects by Relocating Resources
}

\author{
Michał Tomczak $^{1}$ and Piotr Jaśkowski
}

1 Lublin University of Technology, Lublin, Poland, m.tomczak@pollub.pl

2 Lublin University of Technology, Lublin, Poland, p.jaskowski@pollub.pl

\begin{abstract}
Project managers strive to reduce the capital project execution times. Project owners typically insists on quick delivery for financial benefits of early occupation of the built facility (commercial projects), or for reducing public dissatisfaction caused by the works (public projects like road repairs). Construction and civil projects are notorious for delays due to both external and internal factors. The delays require action to be taken to make the project "back on tracks" and finish on time. Given a limited budget and the need for efficient use of resources, the problem of scheduling projects with short completion times is being addressed by a variety of ideas, such as letting non-critical construction processes to be suspended to free resources to more crucial ones, switching to faster but costly construction methods, or allowing changes in the process sequence. This paper presents a new idea on how to accelerate a construction project by relocating some of the workers from non-critical processes to support crews performing critical ones, and possibly by employing additional resources. The authors describe their idea in the form of a mixed-integer linear problem. The model facilitates finding an optimal schedule of processes allowing the relocation of some non-critical or subcontractor resources to support critical crews and meet the baseline execution deadline. A numerical example illustrates the merits of the proposed approach. In practice, the method presented can constitute a valuable tool used in the management of construction projects.
\end{abstract}

(c) 2020 The Authors. Published by Budapest University of Technology and Economics \& Diamond Congress Ltd Peer-review under responsibility of the Scientific Committee of the Creative Construction Conference 2020.

Keywords: construction project management, construction project scheduling, resource allocation, resourceconstrained project scheduling problem, schedule optimization

\section{Introduction and literature review}

Construction projects constitute a particular challenge for managers. The factors that contribute to their unpredictability include susceptibility of construction processes to weather, uniqueness of designs, late effects resulting from the construction process and long-term operation of the building objects, high employee turnover rates, various supply-related logistical problems, and high failure rate of the machines and equipment [1], [2]. On the one hand, these projects are commonly understood as exceptionally difficult to deliver on time. On the other hand, the project owners are rigorous about deadlines specified in the contract. The clients desire to benefit from the outcomes of the investment as quickly as possible. They also need to conform to the bank loan conditions. Thus, they tend to set short and fixed due dates with little understanding for the "unexpected obstacles" likely to be encountered by the contractor.

Managers of construction projects are faced with a challenging task: while meeting the quality and work safety requirements, they need to keep the schedules very tight. An even greater complication in the management process occurs in the event of some schedule risk materialising. The traditional tools and methods such as Critical Path Method (CPM), Precedence Diagramming Method (PDM), Linear Scheduling Method (LSM), Program Evaluation and Review Technique (PERT) prove inadequate for such challenges [3]- 
[9]. The practical schedule crashing requires the planner to ensure efficient use of resources and to minimise costs. The time-cost trade-off belongs to the scheduling problems most frequently addressed in the literature. Even the first scientific paper on CPM focused on it [10]. PDM, the prevailing network technique of current construction practice, is being continuously developed. A catalogue of its potential enhancements, described by Haidu and Isaac [11], includes: maximal relations, splittable activities, logical switches on relations, point-to-point relations, continuous relations, bi-directional relations, and noncontinuous activity time-production functions. Some of them have already been implemented in models presented in the literature on the subject. For instance, discontinuation of non-critical construction processes to make their resources available for the critical ones was adopted in [12] and [13]. Continuous precedence relations were used in [14]. Some authors consider the possibility of changing the manner the processes are executed in search of a trade-off between process cost and time, use extra resources [6], [15], or allow a change in process sequence (soft relationships) in the network model of a project [16], [17].

Tomczak and Jaśkowski developed models that improve the work continuity of the general contractor's inhouse crews, both in non-repetitive [3], [18], and repetitive projects [19]. Their Mixed Integer Linear Problem (MILP) models assumed that subcontractors can be employed to help smooth the general contractor's resources, which optimized the use of in-house labour and improved the harmonisation of work throughout the project.

The model presented by Altuwaim and El-Rayes [12] allowed interrupting secondary construction processes to reduce the overall project duration and to improve the continuity of works. The merits of the model were presented on the example of a repetitive project. García-Nieves et al. [15] developed a mathematical model minimizing the duration and tardiness of repeatable construction projects. The model helped select modes of process execution to accelerate their realisation. Additionally, it allowed the planner to define which tasks can be split if necessary, set fixed precedence relationships and optimum crew size. The authors applied their method to find optimal schedules in a project under seven scenarios of resource availability and continuity conditions.

Hajdu, Lucko, and Su [14] explore the potential of a new type of relationship between the processes, called the continuous precedence relation. It enables the planner to precisely model the processes' overlapping, as it relates the whole processes, and not only their start and finish moments. In addition, this relationship allows the planner to use non-linear activity representations.

A model minimizing the overall cost of road projects, including the costs incurred by road users and surrounding businesses, was presented in the paper [20]. The modelling is done on two levels. The higher level of the system is formulated as a mixed integer problem and its aim is to set the optimum project start date in terms of the overall cost. The lower level of the system is intended to model the decision-making process of drivers in accordance with the project commencement times received from the higher level. The application of the approach can result in a reduction of business disruptions in the vicinity of the project with little increase in travel time.

To reduce work interruptions and improve the organization of work on a construction site, Rzepecki and Biruk [21] included the learning-forgetting effect in their scheduling model with constraints. A similar model [22] was used to minimize the time and cost of the project; the simulation analyses showed an improvement in the organisation of work in terms of the adopted criteria.

Despite the availability of construction management techniques and tools, it appears that the methods which already exist still fail to solve specific problems occurring in the management of construction projects. It is therefore necessary to develop further tools to support construction site managers in resolving emerging issues.

\section{Methods used}

The authors have developed a MILP, which accelerates a construction project by relocating some of the workers from non-critical processes to support crews performing critical ones, and possibly by employing 
additional resources. Due to the constrained length of the paper, the assumptions of the model are presented without the mathematical formulation.

The project needs to be described by an Activity-on-Node (AON) network diagram representing logical dependencies between the processes. In its current form, the model covers only the Finish-to-Start (FS) precedence relations, does not enable defining different calendars for the project and the resources, and operates only in working days. Therefore, the process durations are to be defined as numbers of working days. The planner needs to identify a list of crews capable of performing particular processes. The model assumes that at least some crews are composed of smaller operating units, further referred to as teams. As construction workers are usually trained in more than one trade, the crews are considered multi-skilled. This means that they are capable of delivering several types of processes. A team can be added to a crew to reinforce it. It can also be removed if some other crew needs urgent support. Thus, the planner is required to identify the processes and the crews from which teams are possible to be transferred out, as well as the processes and the crews that may need support in the form of extra teams.

Other assumptions are as follows: each process may be realised only in one execution mode. Subcontracting is possible but constrained: the cost of the subcontracted works may not exceed the cost of these works as if completed by in-house crews. Thus, the model helps take advantage of the general contractor's resources to the highest possible degree if economically justified.

The proposed model aims to reduce the project duration to meet the deadline by relocating selected working teams. The requirement to complete the project before the deadline is introduced as the model's constraint. However, the model's objective function is minimizing the number of instances of the teams' relocation. This is to obtain acceptable schedules while keeping modifications of crew composition to the minimum: changes in crew work routines are likely to generate disruption. The model respects the relationships between individual processes defined by the precedence network and prevents a crew from being assigned to more than one process at a time.

\section{Example and results}

Let us consider an example to illustrate the merits of the model: a project that consists in the erection of two buildings. The construction of each building comprises eight work packages. The general contractor has two crews (GC-1 and GC-2). The GC-2 crew is composed of two identical work teams, GC-2-1 and GC-22. If necessary, one of them may assist the GC-1 crew in executing selected work packages. There are also 5 subcontractor crews marked A to $\mathrm{E}$. The network model of the project and the options of resource assignment are summarised in Figure 1. The process execution times according to resource options are presented in Table 1. Table 2 lists the costs of processes if entrusted to subcontractors. The total cost of subcontracted works must not exceed $€ 900,000$.

A mathematical model of the problem concerning the sample construction project was developed and then solved using The Lingo14.0 software [23]. The calculations were performed on an Intel Core i5, $2 \mathrm{GHz}$ CPU $\mathrm{PC}$, with the solution delivered in 0.2 seconds.

The first analysis was devoted to a "baseline option" without the possibility of relocating the GC-2-2 work team to support the GC-1 crew and without subcontracting packages that physically could be entrusted to in-house crews. Its shortest duration was found to be 72 days with the cost of subcontracted works $€$ 580,000 .

Then the relocation of teams was enabled. The model prompted that the GC-2-2 should be relocated from processes 12 and 13 to processes 4 and 5 . As a result, the duration of the project was reduced by 5 working days still using the same resources as the "baseline option". 


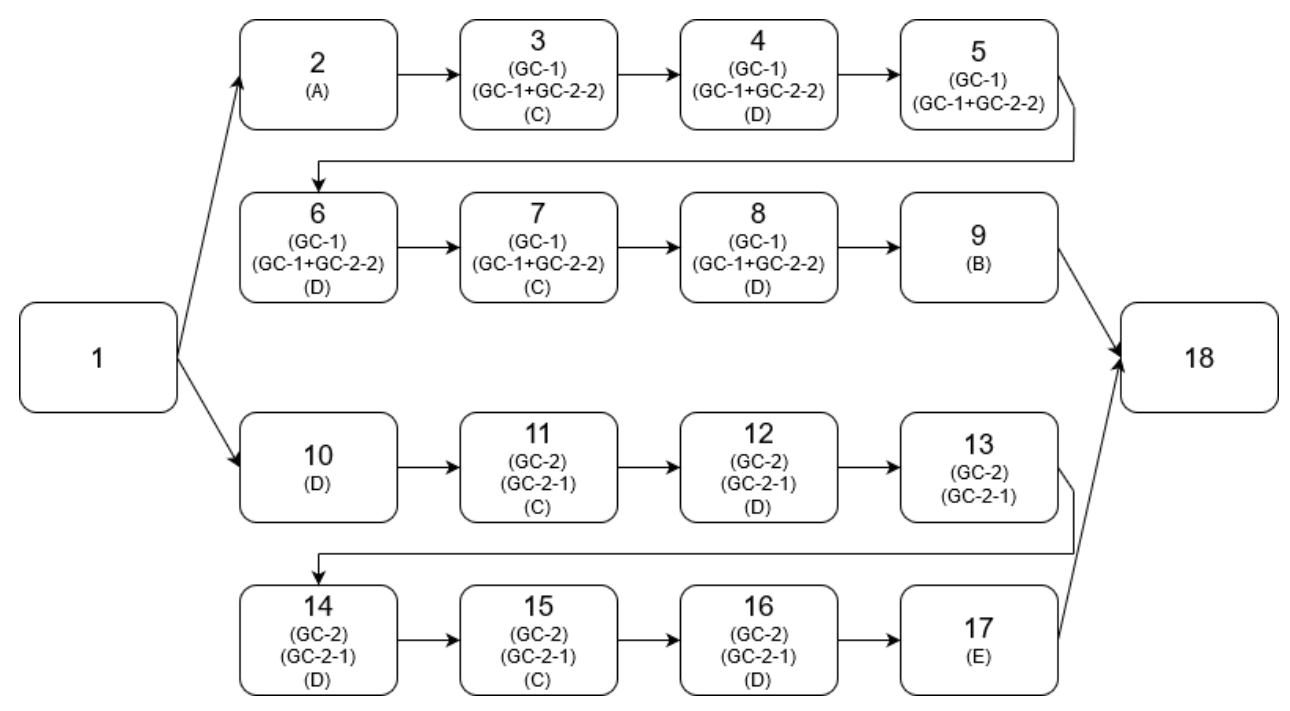

Fig. 1. The network model of the project with possible execution options

Table 1. Process execution times by resource variants

\begin{tabular}{|c|c|c|c|c|c|c|c|c|c|c|c|}
\hline \multirow[t]{2}{*}{ Building No. } & \multirow[t]{2}{*}{ Process No. } & \multirow[t]{2}{*}{ Process } & \multicolumn{9}{|c|}{ Execution processes' durations [in working days] } \\
\hline & & & GC-1 & GC-1+GC-2-2 & GC-2 & GC-2-1 & A & $\mathrm{B}$ & $\mathrm{C}$ & $\mathrm{D}$ & $\mathrm{E}$ \\
\hline & 1 & Start & & & & & & & & & \\
\hline \multirow{8}{*}{ 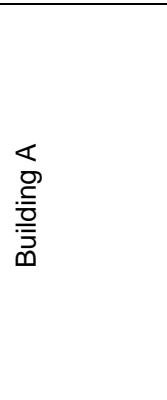 } & 2 & Earthworks & & & & & 3 & & & & \\
\hline & 3 & Foundations & 7 & 5 & & & & & 8 & & \\
\hline & 4 & Foundation walls & 14 & 11 & & & & & & 16 & \\
\hline & 5 & Ground flooring & 7 & 5 & & & & & & & \\
\hline & 6 & Walls & 14 & 11 & & & & & & 7 & \\
\hline & 7 & Floor & 10 & 7 & & & & & 2 & & \\
\hline & 8 & Walls of the attic & 7 & 5 & & & & & & 8 & \\
\hline & 9 & Roof & & & & & & 10 & & & \\
\hline \multirow{9}{*}{ 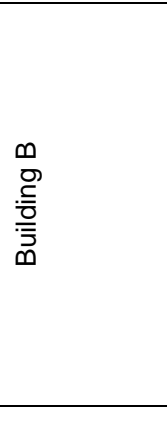 } & 10 & Earthworks & & & & & & & & 1 & \\
\hline & 11 & Foundations & & & 4 & 9 & & & 5 & & \\
\hline & 12 & Foundation walls & & & 7 & 14 & & & & 9 & \\
\hline & 13 & Ground flooring & & & 4 & 9 & & & & & \\
\hline & 14 & Walls & & & 7 & 14 & & & & 8 & \\
\hline & 15 & Floor & & & 5 & 10 & & & 7 & & \\
\hline & 16 & Walls of the attic & & & 4 & 9 & & & & 5 & \\
\hline & 17 & Roof & & & & & & & & & 5 \\
\hline & 18 & Finish & & & & & & & & & \\
\hline
\end{tabular}

Further on, subcontracting was enabled. The employment of subcontractor crews for the execution of the processes 6 and 7 resulted in a reduction of 15 days in the construction duration. Eventually, the project duration was reduced to 52 days, with the cost of the subcontracted works of $€ 850,000$. A detailed Gantt chart for the optimal schedule of the sample construction project is presented in Fig. 2.

\section{Conclusions}

Managing construction projects is a challenge, and the consequences of wrong decisions are particularly costly. There is a need for reliable support for decision making. The method of reducing the project duration described in this paper may serve as one of such practical tools. It may be used for re-scheduling projects subject to serious disruption when one needs to find a way to speed up while relying on a fixed pool of resources. The method may also be used by contractors at the bidding stage to analyse how to make the 
best use of the resources at hand and how to subcontract economically while meeting the contractual deadlines.

Table 2. The execution costs of the individual processes realised by the subcontractor crews

\begin{tabular}{|c|c|c|c|c|c|c|c|}
\hline \multirow[t]{2}{*}{ Building No. } & \multirow[t]{2}{*}{ Process No. } & \multirow[t]{2}{*}{ Process } & \multicolumn{5}{|c|}{ Execution processes' cost [in $1000 €$ ] } \\
\hline & & & $A$ & B & $\mathrm{C}$ & $\mathrm{D}$ & $E$ \\
\hline & 1 & Start & & & & & \\
\hline \multirow{8}{*}{ 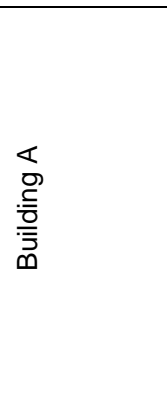 } & 2 & Earthworks & 90 & & & & \\
\hline & 3 & Foundations & & & 100 & & \\
\hline & 4 & Foundation walls & & & & 80 & \\
\hline & 5 & Ground flooring & & & & & \\
\hline & 6 & Walls & & & & 150 & \\
\hline & 7 & Floor & & & 120 & & \\
\hline & 8 & Walls of the attic & & & & 50 & \\
\hline & 9 & Roof & & 250 & & & \\
\hline \multirow{8}{*}{ 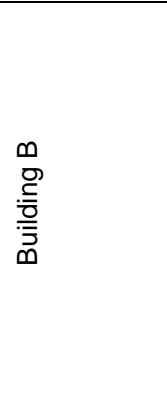 } & 10 & Earthworks & & & & 70 & \\
\hline & 11 & Foundations & & & 70 & & \\
\hline & 12 & Foundation walls & & & & 60 & \\
\hline & 13 & Ground flooring & & & & & \\
\hline & 14 & Walls & & & & 120 & \\
\hline & 15 & Floor & & & 90 & & \\
\hline & 16 & Walls of the attic & & & & 30 & \\
\hline & 17 & Roof & & & & & 170 \\
\hline
\end{tabular}

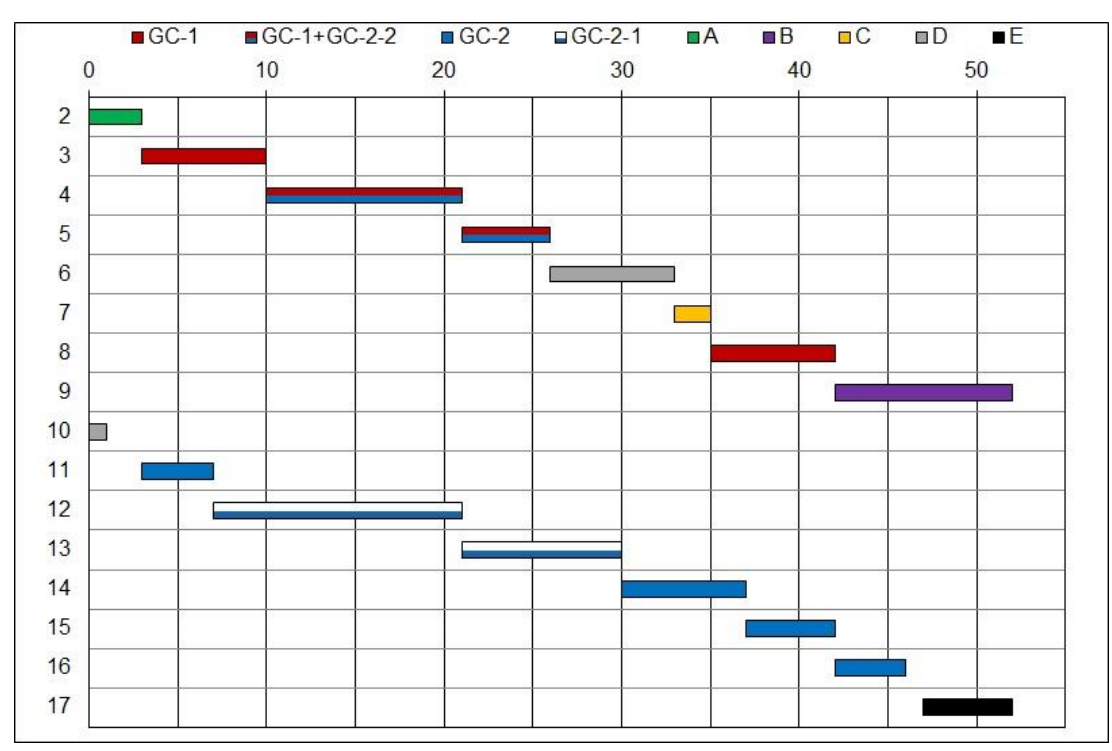

Fig. 2. A Gantt chart for the optimum schedule of the sample construction project

While the idea seems promising, the model is still crude. One of the future directions for its development is adapting it for repeatable projects. The model is going to be expanded to consider process relationships other than Finish-to-Start (FS). Moreover, as it is now purely deterministic, the next issue be addressed is adapting it for risk. Moreover, the model needs to be integrated with the existing scheduling tools for more user-friendly interface and useful options, such as calendars.

\section{Acknowledgements}

The work was financed by the Polish Ministry of Science and Higher Education ILT 63. 


\section{References}

[1] M. Tomczak, "Modeling of the harmonization method for executing a multi-unit construction project," Open Eng., vol. 9, no. 1, pp. 282-291, 2019. https://doi.org/10.1515/eng-2019-0036

[2] M. Tomczak and P. Jaśkowski, "Application of Type-2 Interval Fuzzy Sets to Contractor Qualification Process," KSCE J. Civ. Eng., vol. 22, no. 8, pp. 2702-2713, 2018. https://doi.org/10.1007/s12205-017-0431-2

[3] P. Jaskowski and M. Tomczak, "Minimisation of work gaps for general contractor crews in construction project scheduling," Sci. Rev. Eng. Environ. Sci., vol. 26, no. 2, pp.193-201, 2017. https://doi.org/10.22630/PNIKS.2017.26.2.17

[4] L. Rzepecki, "Optimization of inventory costs management in the construction enterprise," in IOP Conference Series: Materials Science and Engineering, vol. 603, no. 3, p. 032046, 2019. https://doi.org/10.1088/1757-899X/603/3/032046

[5] F. A. E. M. Agrama, "Linear projects scheduling using spreadsheets features," Alexandria Eng. J., vol. 50, no. 2, pp. $179-185,2011$. https://doi.org/10.1016/j.aej.2011.01.018

[6] I. Bakry, O. Moselhi, and T. Zayed, "Optimized scheduling and buffering of repetitive construction projects under uncertainty," Eng. Constr. Archit. Manag., vol. 23, no. 6, pp. 782-800, 2016. https://doi.org/10.1108/ECAM-05-2014-0069

[7] Y. Su and G. Lucko, "Linear scheduling with multiple crews based on line-of-balance and productivity scheduling method with singularity functions," Autom. Constr., vol. 70, pp. 38-50, 2016. https://doi.org/10.1016/j.autcon.2016.05.011

[8] D. Arditi, O. B. Tokdemir, and K. Suh, "Challenges in Line-of-Balance Scheduling," J. Constr. Eng. Manag., vol. 128, no. 6, pp. 545556, 2002. https://doi.org/10.1061/(ASCE)0733-9364(2002)128:6(545)

[9] M. Tomczak and L. Rzepecki, "Evaluation of Supply Chain Management Systems Used in Civil Engineering," in IOP Conference Series: Materials Science and Engineering, vol. 245, no. 7, p. 072005, 2017. https://doi.org/10.1088/1757-899X/245/7/072005

[10] J. Kelly and M. Walker, "Critical path Planning and Scheduling," in Proceedings of the Eastern Joint Computer Conference, pp. 160173, 1959. https://doi.org/10.1145/1460299.1460318

[11] M. Hajdu and S. Isaac, "Sixty years od project planning: history and future," Organization, Technology and Management in Construction, vol 8, pp.1-12, 2016. https://doi.org/10.1515/otmcj-2016-0013

[12] A. Altuwaim and K. El-Rayes, "Minimizing duration and crew work interruptions of repetitive construction projects," Autom. Constr., vol. 88, pp. 59-72, 2018. https://doi.org/10.1016/j.autcon.2017.12.024

[13] P. Jaśkowski, "Resource leveling and construction project scheduling with allowed activity splitting," Acad. J. Sci., vol. 7, no. 3, pp. 439-448, 2017.

[14] M. Hajdu, G. Lucko, and Y. Su, " Singularity functions for continuous precedence relations and nonlinearactivity-time-production functions," Autom. Constr., vol. 79, pp. 31-38, 2017. https://doi.org/10.1016/j.autcon.2017.01.012

[15] J. D. García-Nieves, J. L. Ponz-Tienda, A. Salcedo-Bernal, and E. Pellicer, "The Multimode Resource-Constrained Project Scheduling Problem for Repetitive Activities in Construction Projects," Comput. Civ. Infrastruct. Eng., vol. 33, no. 8, pp. 655-671, 2018. https://doi.org/10.1111/mice.12356

[16] V. Benjaoran, W. Tabyang, and N. Sooksil, "Precedence relationship options for the resource levelling problem using a genetic algorithm," Constr. Manag. Econ., vol. 33, no. 9, pp. 711-723, 2015. https://doi.org/10.1080/01446193.2015.1100317

[17] P. Jaskowski and S. Biruk, "Reducing renewable resource demand fluctuation using soft precedence relations in project scheduling," J. Civ. Eng. Manag., vol. 24, no. 4, pp. 355-363, 2018. https://doi.org/10.3846/jcem.2018.3043

[18] M. Tomczak and P. Jaskowski, "The method of scheduling construction projects increasing the use of resources of the general contractor," in The 13th International Conference "Modern Building Materials, Structures and Techniques": Selected Papers, A. Juozapaitis, A. Daniūnas, and L. Juknevičius, Eds. Vilnius: Vilnius Gediminas Technical University, pp. 683-690, 2019. https://doi.org/10.3846/mbmst.2019.019

[19] M. Tomczak and P. Jaśkowski, "New Approach to Improve General Contractor Crew's Work Continuity in Repetitive Construction Projects," J. Constr. Eng. Manag., vol. 146, no. 5, p. 04020043, 2020. https://doi.org/10.1061/(ASCE)CO.1943-7862.0001824

[20] M. Miralinaghi, W. Woldemariam, D. M. Abraham, S. Chen, S. Labi, and Z. Chen, "Network-level scheduling of road construction projects considering user and business impacts," Comput. Civ. Infrastruct. Eng., pp. 1-18, 2020. https://doi.org/10.1111/mice.12518

[21] Ł. Rzepecki and S. Biruk, "Simulation Method for Scheduling Linear Construction Projects Using the Learning- Forgetting Effect," MATEC Web Conf., vol. 219, p. 04007, 2018. https://doi.org/10.1051/matecconf/201821904007

[22] S. Biruk and L. Rzepecki, "Scheduling Repetitive Construction Processes Using the Learning-Forgetting Theory," in IOP Conference Series: Materials Science and Engineering, vol. 271, p. 112039, 2019. https://doi.org/10.1088/1757-899X/471/11/112039

[23] "LINGO Optimization Modeling Language." LINDO Systems Inc., Chicago, IL, 2014. 